\section{Transtheoretical model on the self-care behavior of hypertension patients: a systematic review}

Self-care behavior of hypertension patients

Masalle Public Health Centre, Enrekang, Indonesia and

Faculty of Nursing, Hasanuddin University, Makassar, Indonesia, and

Elly Lilianty Sjattar and Rosyidah Arafat

Faculty of Nursing, Hasanuddin University, Makassar, Indonesia

\begin{abstract}
Purpose - This review aims to describe the effectiveness of education with the transtheoretical model (TTM)based on the self-care behavior of hypertension patients.

Design/methodology/approach - A systematic literature search was carried out on four databases: PubMed, Science Direct, Cochrane and Grey literature to identify studies reported in English which were published in the last ten years. The literature search was conducted from November 13 to December 10, 2020. Findings - Based on the six studies that have been analyzed, TTM is effective in changing the stage of change and behavior of hypertension patients. These behavioral changes have an impact on the patient's controlled blood pressure. Various types of TTM-based educational interventions can be used, but the tailored behavior intervention is the most appropriate one with a minimum intervention duration of six months. Educational intervention is carried out through combine counseling and education using electronic media.

Originality/value - This review presents the effectiveness of transtheoretical-based health education in changing the self-care behavior of hypertension patients accompanied by evidence-based on its implementation. There is a high and unclear risk of bias on several items influence this systematic outcome. Nevertheless, this review can still provide an overview of the effectiveness of education based on the TTM in hypertension patients about the quality results of the reviewed studies.
\end{abstract}

Keywords Behavior change, Health education, Hypertension, Self-care behavior, Stage of change,

Transtheoretical model

Paper type Review

\section{Introduction}

People with hypertension in the world reach $22 \%$ of the population [1], and it is predicted that it will reach 1.56 bn sufferers in 2025 [2]. Hypertension accounts for half of all deaths due to stroke and heart disease $[1,2]$. To prevent these complications, it is necessary to change the behavior of hypertension patients. The self-care behavior of hypertension patients based on the recommendations of the Joint National Committee (JNC) 7 consists of 6 things, namely: medication adherence, weight loss management, adopting a low-salt diet, routine daily physical activity for 30 minutes, limiting alcohol intake and stop smoking [3]. Adherence to self-care behavior lowers blood pressure, increases the efficacy of antihypertension drugs, minimizes complications and overall mortality associated with hypertension [4]. However, the increasing cases of hypertension are not matched with a good self-care behavior by hypertension sufferers.

(C) Hasriani, Elly Lilianty Sjattar and Rosyidah Arafat. Published in Journal of Health Research. Published by Emerald Publishing Limited. This article is published under the Creative Commons Attribution (CCBY 4.0) licence. Anyone may reproduce, distribute, translate and create derivative works of this article (for both commercial and non-commercial purposes), subject to full attribution to the original publication and authors. The full terms of this licence may be seen at http://creativecommons. org/licences/by/4.0/legalcode
Received 20 January 2021 Revised 4 April 2021 Accepted 28 April 2021 
JHR

36,5

848

Various factors influence the self-management behavior of hypertension patients, including trust in the effectiveness of therapeutic, self-efficacy, social support and health education [5]. Health education has the most dominant influence on self-management behavior (SMB) [5]. Appropriate educational interventions can increase a person's knowledge, attitudes, skills and self-efficacy to independently perform self-care behavior [6]. Without proper intervention, challenges and problems arising during the implementation can decrease self-efficacy and willingness to maintain self-care behavior [7]. Hence, appropriate intervention is required to educate the hypertension patients to obtain compliance in behavioral change.

Providing health education can be done using various approaches, one of which is the transtheoretical model (TTM). TTM describes the stages of formation or behavior change by including four main components, namely, the stages of change, the processes of change, decisional balance and self-efficacy [8]. In its implementation, the provision of TTM-based education is based on the stages of change for each patient. The stages of change consist of pre-contemplation, contemplation, preparation, action and maintenance $[8,9]$.

TTM has been widely used in changing patient behavior as evidenced by several previous reviews. Reviewed the effectiveness of TTM in the prevention of chronic disease [10], activity changes in self-management for people with DM Type 2 [11] and in changing physical activity behavior [12]. Meanwhile, hypertension itself is still limited to experimental research. No researcher has systematically reviewed the effectiveness of TTM in improving the self-care behavior of hypertension patients. Therefore, the research question is whether the TTM approach is effective in improving the self-care behavior of hypertension patients.

The authors are interested in examining the effectiveness of the TTM in improving the self-care behavior of hypertension patients which based on the form of changes in patient behavior stages, changes in blood pressure, intervention, duration of intervention, media and method used from the TTM intervention.

\section{Methods}

This study is a systematic review using the Preferred Reporting Items for Systematic Reviews and Meta-Analyses (PRISMA) guideline checklist in writing a systematic review report. The writer used the PRISMA guidelines for the review protocol and study selection [13]. This review has been registered in the Prospective Register of Systematic Review (PROSPERO) with registration number CRD42020210423.

\section{Eligibility criteria}

Studies meet the following criteria: (1) the population is hypertension sufferers aged over 18 years; (2) all types of intervention are based on a TTM; (3) it is research with control; (4) all studies discuss the results of research on self-care behavior (5) experimental studies compare two or more groups; (6) studies conducted within the last ten years (2010-2021) and (7) studies from all countries will be accepted as long as it is in English.

Studies were excluded if: (1) there is more than one intervention in the intervention group; (2) full text is not available; (3) articles are duplicated.

\section{Search strategy}

The literature search used the PubMed, Science Direct, Cochrane Library and Grey Literature databases with a span of 2010 to 2020 . We choose articles published in the last ten years expecting to provide evidence for health workers in choosing educational methods with more 
updated information. The literature search was conducted from November 13 to December 10, 2020. The searching for articles using keywords:

P: hypertension OR high blood pressure OR elevated blood pressure OR hypertension

I: transtheoretical model OR trans-theoretical model OR stage of change OR behavior change

C: control OR usual care OR standard education

O: self-care behavior OR self-care activity OR medication adherence OR weight management OR low salt diet OR reduce alcohol OR stop smoking OR physical activity
Self-care behavior of hypertension patients

\section{Study selection}

Two reviewers (HSR and ELS) identified article titles and abstracts from the database for relevant studies. The full text of the relevant articles was then retrieved to assess inclusion. Any resulting difference was then discussed with the third reviewer (RA) until a consensus of all reviewers was reached.

\section{Assessment of the article quality}

Critical appraisal used for the randomized controlled trial (RCT) design used the instrument of Critical Appraisal Skills Program Tools (CASP) [14]. The quality of studies with a quasiexperimental design was assessed using the instrument of Joanna Briggs Institute (JBI) Critical Appraisal Checklist for Quasi-Experimental Studies [15]. This review uses a level of evidence with the reference to the Center for Evidence-Based Management (CEBM). The Cochrane Effective Practice and Organisation of Care (EPOC) was used to assess the risk of bias [16]. This assessment was carried out by three observers (HSR, ELS and RA). After the following discussion, we excluded irrelevant research and research that did not meet the set goals.

\section{Data extraction}

The articles that were selected for full-text review were independently extracted by three reviewers at different places and times using a data extraction sheet. This list contained information on authors, year, country of origin, research design, study objectives, research outcomes and conclusions. After completing the mapping process, we synthesized the results for summary findings related to the observed variables. The three reviewers discuss to analyze the similarities and differences of the selected studies to present a cohesive summary.

\section{Ethical consideration}

Ethical approval was obtained from the Stikes Nani Hasanuddin ethics board (007/STIKES$\mathrm{NH} / \mathrm{KEPK} / \mathrm{XI} / 2020$ ).

\section{Results}

From the total number of articles, 1,612 articles were identified, and 6 articles met the criteria. The results of the study selection can be seen in Figure 1 . The six studies were carried out in diverse countries with varied sample from 60 patients to 533 patients who mostly were women over 50 years of age (Table 1). 

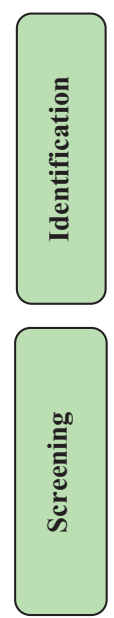

Figure 1.

PRISMA flow chart
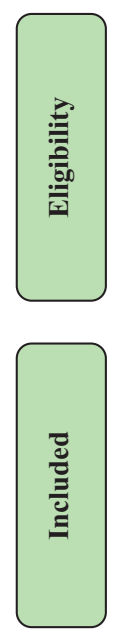

Records identified via database quest: Pubmed ( $n=161)$, Science Direct $(n=896)$, Cochrane Library $(n=538)$ $\sum n=1.595$
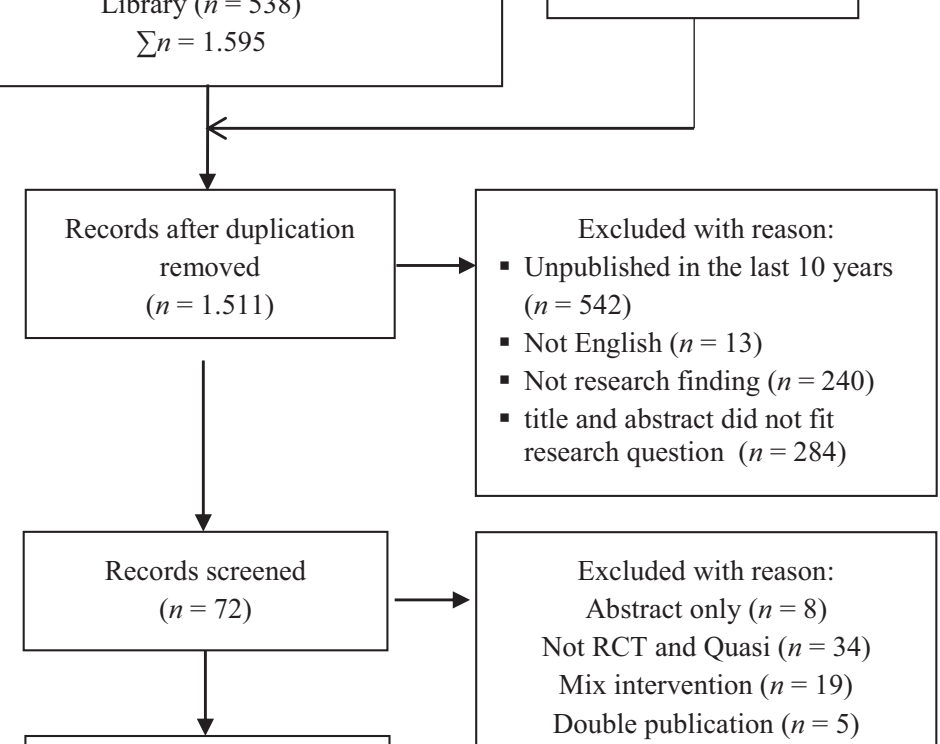
$(n=7)$

Full text articles assessed for eligibility $(n=6)$

Studies included in synthesis $(n=6)$

\begin{tabular}{lllrrrr}
\hline & & \multicolumn{5}{c}{ Sex } \\
Author, year & Country & Design & Sample & Men & Woman & Age (mean \pm SD) \\
\hline Rodriguez et al., 2019[21] & USA & RCT & 533 & 98.67 & 1.33 & $66 \pm 0.1$ \\
Yasutake et al., 2018 [20] & Japan & RCT & 78 & 47.43 & 52.57 & $54.05 \pm 7.01$ \\
Liu et al., 2018 [18] & Kanada & RCT & 128 & 64.2 & 35.8 & $48.5 \pm 94$ \\
Motlagh et al., 2017 [17] & Iran & RCT & 78 & 52.3 & 47.7 & $56.9 \pm 0.8$ \\
Karupaiah et al., 2015 & Malaysia & Quasi & 209 & 1538 & 84.62 & $58 \pm 17.4$ \\
[19] & & Eksperimen & & & & \\
Saputri et al., 2016 [22] & Indonesia & Quasi & 60 & 28.33 & 71.67 & $50-59(43 \%)$ \\
& & Eksperimen & & & & \\
& & & &
\end{tabular}

Table 1.

Studies characteristic
[19] 
Changes in the stage of change

Of the six articles reviewed, there were four articles examining changes in the stage of change of hypertension patients. The four articles show that TTM-based education is effective in changing the stage of change of hypertension patients toward action and maintenance (Table 2).
Self-care behavior of hypertension patients

\section{Changes in behavior}

In this review, no studies were examining the overall self-care behavior of hypertension patients (Table 2). There are several types of changes in the self-care behavior of hypertension patients, including physical activity [17-19], a low-salt diet [19, 20], Dietary Approaches to Stop Hypertension (DASH) diet [21], fruit and vegetable consumption [18, 19] and medication adherence [22].

\section{Changes in blood pressure}

Of the six articles reviewed, five articles examined changes in blood pressure after administering TTM-based interventions (Table 2). Of the five studies, four of them showed significant changes in blood pressure both in the baseline measurements and with the control group [17-19, 22], whereas one article showed no change in blood pressure [20].

\section{Type of intervention}

Among the six articles reviewed, there were four types of interventions used, namely technology-based education, education using independent salt monitoring tools, theorybased training education and community-based education (Supplementary material). Technology-based educational interventions were carried out in three studies, namely total body irradiation (TBI) based on telephone [21], via email [18], and through counseling and short messaging service (SMS) [22]. Theory-based training education is carried out by Motlagh et al. [17]. There are also educational interventions with independent monitoring tools [20] and interventions that are summarized in the Cardiovascular Risk Factors Intervention Strategies (CORFIS) program [19]. Of the six studies reviewed, five studies explained the educational interventions given and were adjusted to the stages of changes in the patient's behavior [1719, 21, 22]. Meanwhile, other studies do not specify whether the intervention given is following the stages of behavior change [20]. However, these studies continue to assess the stages of behavior change before and after the intervention.

\section{Duration of education}

The educational duration used from the six articles was also different (Supplementary material). The longest and most used studies in this review were for 6 months [19, 21], 4 months [18], 3 months [17] and 4 weeks [20, 22].

\section{Educational media and methods used}

The use of media and educational methods was also different in the six articles reviewed. Methods and media adjust to the type of intervention given (Supplementary material). Technology-based interventions were used by three studies which were divided into the use of media in the form of the telephone [21], e-mail[18] and SMS [22]. There are also studies using a salt excretion monitor [20], brochures [19] and through training using power points [17].

\section{Critical appraisal and level of evidence}

There were four studies assessed using the CASP randomized controlled trial checklist. All four studies demonstrated good article quality with a level of evidence la and a recommendation 


\begin{tabular}{l} 
JHR \\
36,5 \\
$\mathbf{8 5 2}$ \\
\hline
\end{tabular}

청융

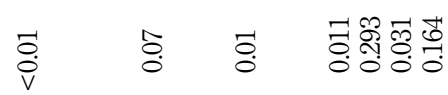

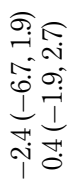

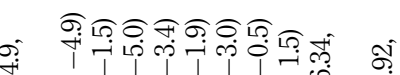

I.

GIIIIIIIIo

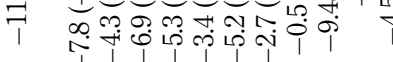

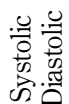

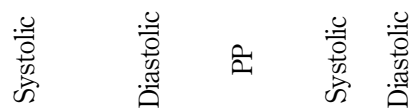

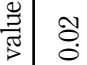

菅

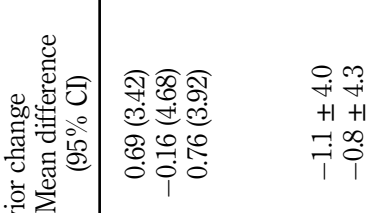

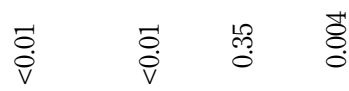

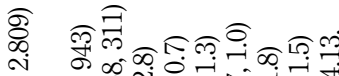

on

8ू

I II IIISIo

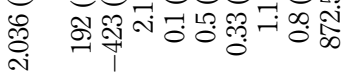

离

Table 2.

The effectiveness of TTM on the changing the stage of change, behavior and blood pressure
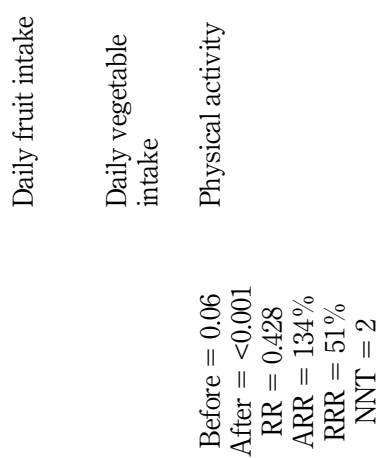

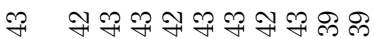

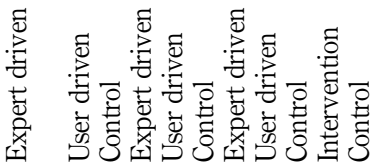

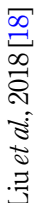

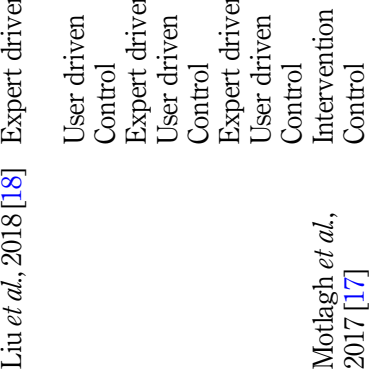

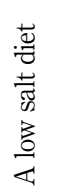

:总

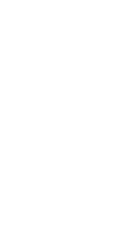

พั ตื

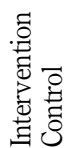




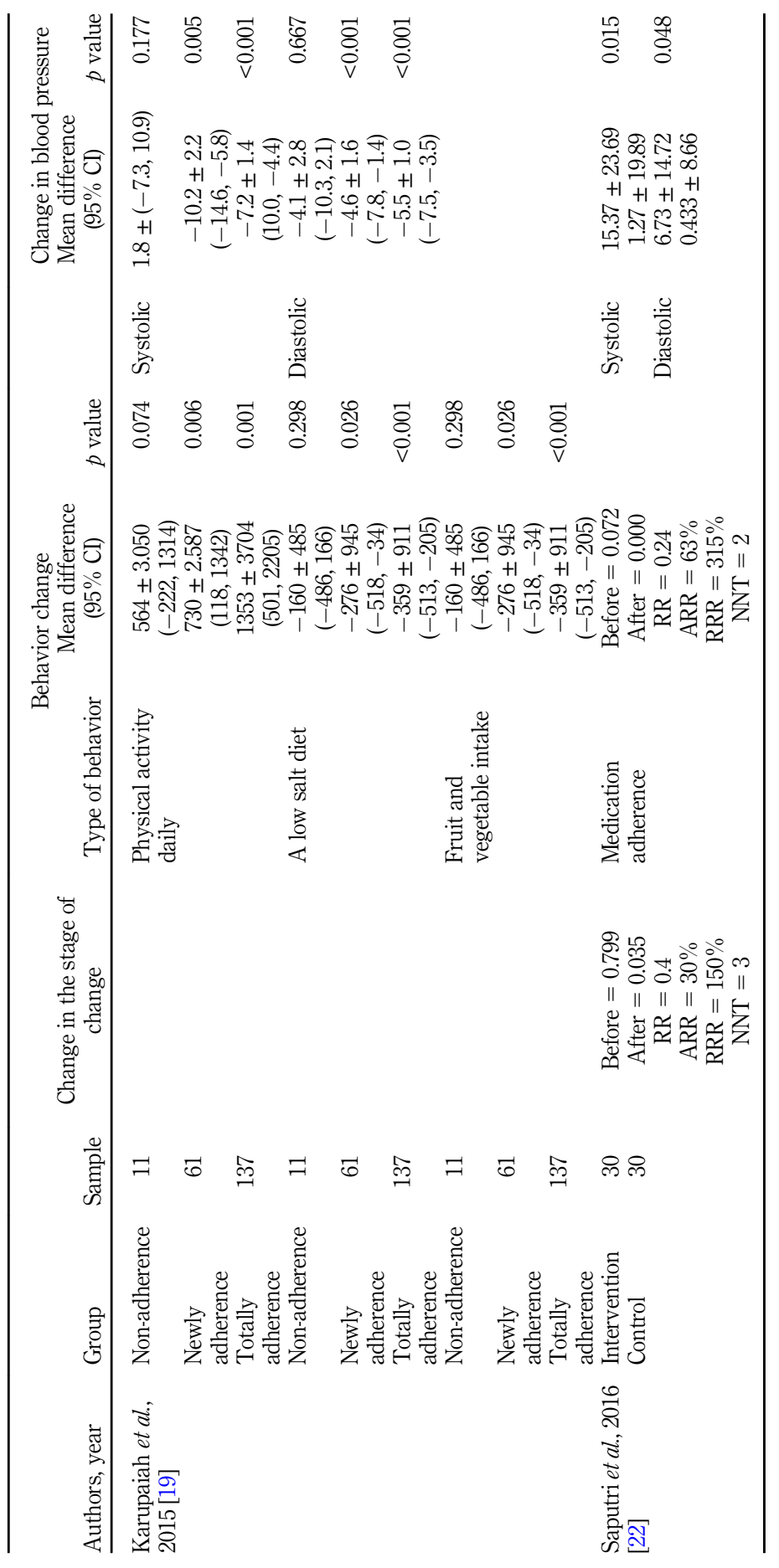

Self-care behavior of hypertension patients

853

Table 2. 
JHR

36,5 level of A. Meanwhile, the two studies reviewed with the JBI critical appraisal checklist for quasi-experimental studies showed good quality articles but at level $2 \mathrm{~b}$ and level of recommendation $\mathrm{B}$.

\section{Risk of bias}

Of the six articles reviewed, two was not randomized in selecting the sample and determining the intervention and control groups. For the aspects of allocation concealment, baseline outcome, baseline characteristics and incomplete data outcome, all of studies present a low risk of bias. Furthermore, the aspect of knowledge of the allocated interventions was adequately prevented during the study which in this case, only four articles had a low risk of bias. Two studies were unclear because they did not explain whether the sample, researchers or health workers were blinded. On the protection against contamination aspect, one article has an unclear risk of bias because of the possibility that communication between professionals' intervention and control could have occurred. As for other sources of bias, one article has the risk of unclear bias because the limitations of the study are unknown.

\section{Discussion}

This systematic review aims at describing the effectiveness of education based on the TTM in improving self-care behavior of hypertension patients based on changes in patient behavior stages, changes in blood pressure after the intervention, a form of intervention, duration of intervention, media and method used of intervention.

The results indicate that the behavioral stages of hypertension patients changed significantly after receiving TTM-based education. The education provided can change patient behavior in a positive direction, namely compliance. Behavioral change is complex and unfolds in various stages. Individuals usually adapt these change processes according to the progress they have made to change their behavior [23]. To change a person's behavior, educators referring to the change process existing at each stage of behavior change where there are a decision-making process and changes in self-efficacy [9]. The application of the core construct of TTM can change the patient's behavior to become obedient [10, 24-26]. It is different from the results of the review by Friman et al. [23] who found that the TTM-based education implemented was still able to change a person's behavior even though the intervention provided did not refer to a person's stages of change. Thus, TTM-based education is effectively used by health educator in changing the self-care behavior of hypertension patients, but the choice of intervention still requires further research.

Changes in the behavior of hypertension patients have an impact on a significant reduction in blood pressure after receiving TTM-based education. Changes in blood pressure occur in systolic and diastolic blood pressure. Blood pressure is influenced by various factors, and it can change at any time [24-26]. Patient adherence to self-care behavior has an impact on lowering blood pressure [27-29]. Research in this review examined that the low-salt diet behavior showed an insignificant reduction in blood pressure in the intervention group. It is associated with the many triggers of changes in blood pressure that can change over time [24-26], and it is not the main goal of a low-salt diet [7]. Therefore, a combination of several targets of behavior change is required to reduce the blood pressure of hypertension patients.

The types of intervention used in each study varied. Although the various types of interventions are carried out, the implementation of each intervention still refers to the stages of behavior change. For developing countries, Internet-based interventions, especially email, are still difficult to implement [30-32]. The population is still less exposed to technology, the ability to access networks is still limited and the majority of hypertension sufferers are 
elderly. The TBI intervention has a lower risk of bias, a larger sample size and the duration of the study matching the duration of the TTM. Therefore, it is preferable to be applied. Education including teaching, skills, increasing self-efficacy and providing motivation is required in increasing hypertension patient compliance [29]. The motivation-based program had a promising outcome in terms of behavior change [33]. Hence, telephone-based TBI intervention is the right type of intervention in providing TTM-based education to hypertension patients.

The duration of the TTM-based educational interventions used was different and at most under six months. Changing a person's behavior takes a long time, especially if the behavior has become a habit [34]. Even so, the interventions in this review were able to change the patient's behavior. It is just that the achievement of behavior change at the maintenance stage is still in doubt. Educational interventions will be meaningful until they reach the maintenance stage if education is provided with a minimum duration of 24 weeks [35]. Furthermore, longer duration of education was more effective than educational interventions of less than six months [36]. Thus, health educators in educating require intervention for at least six months.

Electronic media is the most widely used in this review. Education using electronic media can improve self-care for hypertension patients [32, 34, 37] even though Internet-based mobile applications do not apply to all age levels and all different patient characteristics [30-32]. The method that is mostly used in this research is combined counseling and education. Participatory educational methods can help educators convince patients to have better selfcare in controlling the disease [29]. Encouraging family participation is crucial for increasing patient adherence [38]. Therefore, health educators need to educate hypertension patients by combined counseling and education methods using electronic media.

\section{Limitation}

After repeated assessments, there is a high and unclear risk of bias on several items, especially performance bias, and detection bias influencing this systematic outcome. Some of the educational interventions in this review were found to be combined with counseling that could bias the results of this study. Nevertheless, this review can still provide an overview of the effectiveness of education based on the TTM in hypertension patients especially about the quality results of the reviewed studies. Continuing with meta-analysis as better evidence, further research is required using a more considerable number of review samples and research with homogeneous studies employing the identical type of intervention and setting.

\section{Conclusions}

The purpose of this systematic review is to prove the effectiveness of education based on a TTM in changing the self-care behavior of hypertension patients in terms of changes in stage of change, changes in blood pressure, types of intervention, duration, methods and media used. All studies in this review show a significant change in behavior after the provision of TTM-based education marked by a change in the stages of behavior toward action and maintenance. In educating, health workers need to assess the stages of change for each patient and provide interventions based on that. Changes in the behavior of hypertension patients have an impact on the patient's controlled blood pressure. Controlling blood pressure requires a combination of self-care behavior items. Health educators are necessary to carry out telephone-based TBI interventions with a minimum duration of six months. TTM-based educational interventions are provided with a combination of the counseling and education method using electronic media at the community level.

Conflicts of Interest: None

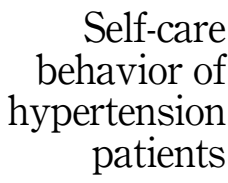

855 
JHR

36,5

856

\section{References}

1. World Health Organization [WHO]. Hypertension. [updated 2019 Sep 13; cited 2020 Dec]. Available from: https://www.who.int/news-room/fact-sheets/detail/hypertension.

2. Forouzanfar MH, Liu P, Roth GA, Ng M, Biryukov S, Marczak L, et al. Global burden of hypertension and systolic blood pressure of at least 110 to $115 \mathrm{~mm} \mathrm{Hg}, 1990-2015$. JAMA. 2017; 317(2): 165-82. doi: 10.1001/jama.2016.19043.

3. National High Blood Pressure Education Program. The seventh report of the joint national committee on prevention, detection, evaluation, and treatment of high blood pressure. Bethesda, MD: National Heart, Lung, and Blood Institute; 2004.

4. Weber MA, Schiffrin EL, White WB, Mann S, Lindholm LH, Kenerson JG, et al. Clinical practice guidelines for the management of hypertension in the community: a statement by the American Society of Hypertension and the International Society of Hypertension. J. Clin. Hypertens 2014; 16(1): 14-26. doi: 10.1111/jch.12237.

5. Mulyati L, Yeti K, Sukamrini L. Analysis of factors effecting self-management behaviour among patients with hypertension. Jurnal Keperawatan Padjadjaran. 2013; 1(2): 112-23.

6. Irwan AM, Kato M, Kitaoka K, Ueno E, Tsujiguchi H, Shogenji M. Development of the saltreduction and efficacy-maintenance program in Indonesia. Nurs Health Sci. 2016; 18(4): 519-32. doi: $10.1111 /$ nhs. 12305 .

7. Bandura A. Social foundations of thought and action: a social cognitive theory. Englewood Cliffs, New Jerssey, NJ: Prentice-Hall; 1986.

8. Prochaska JO, Johnson S, Lee P. The transtheoretical model of behavior change. In: Shumaker SA, Ockene JK, Riekert KA (Eds). The handbook of health behavior change. 3rd ed. New York, NY: Springer; 2009. p. 59-83.

9. Prochaska JO. Transtheoretical model of behavior change. In: Gellman MD, Turner JR, (Eds). Encyclopedia of behavioral medicine. New York, NY: Springer New York; 2013. p. $1997-2000$.

10. Hashemzadeh M, Rahimi A, Zare-Farashbandi F, Alavi-Naeini AM, Daei A. Transtheoretical model of health behavioral change: a systematic review. Iran J Nurs Midwifery Res. 2019; 24(2): 83-90. doi: 10.4103/ijnmr.IJNMR_94_17.

11. Arafat Y, Mohamed Ibrahim MI, Awaisu A. Role of pharmacists in the application of the transtheoretical model approach to enhance medication adherence in chronic diseases. J Pharm Pract Res. 2016; 46(4): 338-41. doi: 10.1002/jppr.1198.

12. Chen H, Wang Y, Liu C, Lu H, Liu N, Yu F, et al. Benefits of a transtheoretical model-based program on exercise adherence in older adults with knee osteoarthritis: a cluster randomized controlled trial. J Adv Nurs. 2020; 76(7): 1765-79. doi: 10.1111/jan.14363.

13. Moher D, Liberati A, Tetzlaff J, Altman DG. Preferred reporting items for systematic reviews and meta-analyses: the PRISMA statement. PLoS Med. 2009; 6(7): e1000097. doi: 10.1371/journal.pmed. 1000097.

14. Critical Appraisal Skills Programme [CASP]. CASP randomised controlled trial checklist. [cited 2020 Dec]. Available from: https://casp-uk.net/casp-tools-checklists/.

15. Joanna Briggs Institute [JBI]. JBI critical appraisal checklist for quasi-experimental studies. [cited 2020 Dec]. Available from: https://jbi.global/assets/docs/critical-appraisal-tools/JBI_QuasiExperimental_Appraisal_Tool2017.pdf.

16. Higgis J, Thomas J, Chandler J, Cumpston M, Li T, Page M, et al. Cochrane handbook for systematic reviews of interventions version 6.2. [updated 2021 Feb; cited 2020 Dec]. Available from: https://training.cochrane.org/handbook.

17. Motlagh Z, Hidarnia A, Kaveh MH, Kojuri J. Effect of theory-based training intervention on physical activity and blood pressure in hypertensive patients: a randomized control trial. Iran Red Crescent Med J. 2017; 19(7): e55610. doi: 10.5812/ircmj.55610. 
18. Liu S, Brooks D, Thomas SG, Eysenbach G, Nolan RP. Effectiveness of user- and expert-driven web-based hypertension programs: an RCT. Am J Prev Med. 2018; 54(4): 576-83. doi: 10.1016/j. amepre.2018.01.009.

19. Karupaiah T, Wong K, Chinna K, Arasu K, Chee WS. Metering self-reported adherence to clinical outcomes in malaysian patients with hypertension: applying the stages of change model to healthful behaviors in the CORFIS study. Health Educ Behav. 2015; 42(3): 339-51. doi: 10.1177/ 1090198114558588.

20. Yasutake K, Miyoshi E, Misumi Y, Kajiyama T, Fukuda T, Ishii T, et al. Self-monitoring of urinary salt excretion as a method of salt-reduction education: a parallel, randomized trial involving two groups. Public Health Nutr. 2018; 21(12): 2164-73. doi: 10.1017/s1368980018000095.

21. Rodriguez MA, Friedberg JP, DiGiovanni A, Wang B, Wylie-Rosett J, Hyoung S, et al. A tailored behavioral intervention to promote adherence to the DASH diet. Am J Health Behav. 2019; 43(4): 659-70. doi: 10.5993/ajhb.43.4.1.

22. Saputri ZG, Akrom A, Darmawan E. Counseling and motivational short text messages increase adherence and behavioral changes in patient with hypertension. Jurnal Kedokteran dan Kesehatan Indonesia. 2016; 7(3): 87-94. doi: 10.20885/JKKI.Vol7.Iss3.art3.

23. Friman M, Huck J, Olsson LE. Transtheoretical model of change during travel behavior interventions: an integrative review. Int J Environ Res Public Health. 2017; 14(6): 581. doi: 10.3390/ ijerph14060581.

24. Smeltzer SC, Bare BG. Buku Ajar Keperawatan Medikal Bedah Brunner \& Suddarth. 8th ed. Jakarta: EGC; 2013.

25. Kowalak JP, Welsh W, Mayer B. Pathophysiology textbook. Jakarta: EGC; 2011.

26. Zhou B, Webster J, Fu LY, Wang HL, Wu XM, Wang WL, et al. Intake of low sodium salt substitute for 3years attenuates the increase in blood pressure in a rural population of North China - a randomized controlled trial. Int J Cardiol. 2016; 215: 377-82. doi: 10.1016/j.ijcard.2016.04.073.

27. Breaux-Shropshire TL, Brown KC, Pryor ER, Maples EH. Relationship of blood pressure selfmonitoring, medication adherence, self-efficacy, stage of change, and blood pressure control among municipal workers with hypertension. Workplace Health Saf. 2012; 60(7): 303-11. doi: 10. 1177/216507991206000704.

28. Warren-Findlow J, Krinner LM, Vinoski Thomas E, Coffman MJ, Gordon B, Howden R. Relative and cumulative effects of hypertension self-care behaviors on blood pressure. West J Nurs Res. 2020; 42(3): 157-64. doi: 10.1177/0193945919851111.

29. Daniali SS, Eslami AA, Maracy MR, Shahabi J, Mostafavi-Darani F. The impact of educational intervention on self-care behaviors in overweight hypertensive women: a randomized control trial. ARYA Atheroscler. 2017; 13(1): 20-8.

30. Schweier R, Romppel M, Richter C, Grande G. Dissemination strategies and adherence predictors for web-based interventions-how efficient are patient education sessions and email reminders? Health Educ Res. 2016; 31(3): 384-94. doi: 10.1093/her/cyw019.

31. Kitt J, Fox R, Tucker KL, McManus RJ. New approaches in hypertension management: a review of current and developing technologies and their potential impact on hypertension care. Curr Hypertens Rep. 2019; 21(6): 44. doi: 10.1007/s11906-019-0949-4.

32. Liu S, Dunford SD, Leung YW, Brooks D, Thomas SG, Eysenbach G, et al. Reducing blood pressure with Internet-based interventions: a meta-analysis. Can J Cardiol. 2013; 29(5): 613-21. doi: 10.1016/j.cjca.2013.02.007.

33. Chalermrueangrong J, Preechawong S. Effect of the motivation program to quit smoking in Royal Thai Air Force officers with non-communicable disease risks. J Health Res. 2019; 33(5): 416-24. doi: 10.1108/Jhr-11-2018-0143.

34. Jamshidnezhad A, Kabootarizadeh L, Hoseini SM. The effects of smartphone applications on patients self-care with hypertension: a systematic review study. Acta Inform Med. 2019; 27(4): 263-7. doi: 10.5455/aim.2019.27.263-267. 
JHR

36,5

858
35. Fjeldsoe B, Neuhaus M, Winkler E, Eakin E. Systematic review of maintenance of behavior change following physical activity and dietary interventions. Health Psychol. 2011; 30(1): 99-109. doi: 10.1037/a0021974.

36. Neville LM, O'Hara B, Milat A. Computer-tailored physical activity behavior change interventions targeting adults: a systematic review. Int J Behav Nutr Phys Act. 2009; 6: 30. doi: 10.1186/14795868-6-30.

37. McLean G, Band R, Saunderson K, Hanlon P, Murray E, Little P, et al. Digital interventions to promote self-management in adults with hypertension systematic review and meta-analysis. J Hypertens. 2016; 34(4): 600-12. doi: 10.1097/hjh.0000000000000859.

38. Woodham N, Taneepanichskul S, Somrongthong R, Auamkul N. Medication adherence and associated factors among elderly hypertension patients with uncontrolled blood pressure in rural area, Northeast Thailand. J Health Res. 2018; 32(6): 449-58. doi: 10.1108/Jhr-11-2018-085.

\section{Appendix}

Supplementary material is available online for this article.

\section{Corresponding author}

Hasriani can be contacted at: hasriani.ners08@gmail.com

For instructions on how to order reprints of this article, please visit our website: 